\title{
Analysis and Research of Monitoring and Controlling on Greenhouse Environment in Facility Agriculture
}

\author{
YAO Qi-guo \\ School of Mechanical \& Electrical Engineering \\ Zhejiang Ocean University \\ Zhejiang, Zhoushan, China,316000 \\ yaoqiguo@163.com
}

\author{
LIU Yu-liang \\ School of Mechanical \& Electrical Engineering \\ Zhejiang Ocean University \\ Zhejiang, Zhoushan, China,316000 \\ lyl_zjou@126.com
}

\begin{abstract}
Along with the development of facility agriculture technology, the greenhouse industry constantly upgraded. Applying sensor technology, electronic technology, communication technology and network technology to regulate and control the greenhouse environmental factors will greatly boost greenhouse industry economic benefit. This paper do some research and analysis of monitoring and controlling on greenhouse environment in facility agriculture.
\end{abstract}

Keywords-temperature control; environmental factors; sensors; mode of controlling

\section{INTRODUCTION}

Along with the development of social economy, facility agriculture which acts as an important way to develop agriculture continuously is taken care more and more by the countries all over the world. Greenhouse production broke through the traditional mode of agricultural, avoided a lot of restrict such as region, natural environment and climate, so it became a new kind of planting technology of crops, and had important significance on the development of agriculture ${ }^{[1]}$.

Modern greenhouse technology started late in China, relatively fell behind in measurement and controlling comprehensive environment. Otherwise, some other country's greenhouse technology has reached a higher level as Holland, Japan, America, England, and Israel. For example, in Israel, the controlling system of greenhouse environment could choose different types of controller and peripheral equipments according to the characteristics of the controlled object, so as to fully meet the internal environmental needs of modern greenhouse. Thus, using sensor technology, electronic technique, communication technology and network technique to research the system which can regulator and control the air temperature, humidity, $\mathrm{CO}_{2}$ concentration, illumination intensity of greenhouse possess long-term significance.

\section{INFLUENCE OF ENVIRONMENTAL}

\section{FACTORS TO GREENHOUSE ENVIRONMENT}

The environmental factors which affect the growth of crops consist of temperature, humidity, sunshine, and concentration of $\mathrm{CO}_{2}$. The temperature is one of the most important environmental factors to the growth of crops, it affects the whole internal physiological changes of crops.
Suitable air humidity and soil humidity are the important conditions of crops healthy growth. The $\mathrm{CO}_{2}$ is the carbon source of crops' normal physiological activity, and the concentration of $\mathrm{CO}_{2}$ will affect crop's photosynthesis, further more will affect their growth, output and quality. The sunshine is an energy source of photosynthesis and it restricts crops growth. All these environmental factors of greenhouse environment have certain coupling, such as that heat up may reduce its humidity, otherwise increase humidity may reduce its temperature, and so on ${ }^{[2]}$. So it should be comprehensive considered in controlling greenhouse environment.

\section{SIGNAL ACQUISITION ELEMENTS OF ENVIRONMENTAL FACTORS}

In measuring and controlling temperature system, such elements as thermocouple, platinum resistor and thermal resistor are frequently used. In recent years, the PN junction temperature sensor appeared. The humidity measuring system includes resistance-type and capacitance-type humidity sensor, TDR-type and FDR-type soil humidity sensor. The photoelectric device includes light-sensitive diode and light-sensitive triode, etc. The gas sensor is called electric nose which acts as the animals' sense of smell organ, the TGS4160-type $\mathrm{CO}_{2}$ sensor is often used to measure the concentration of $\mathrm{CO}_{2}$ in greenhouse ${ }^{[3]}$.

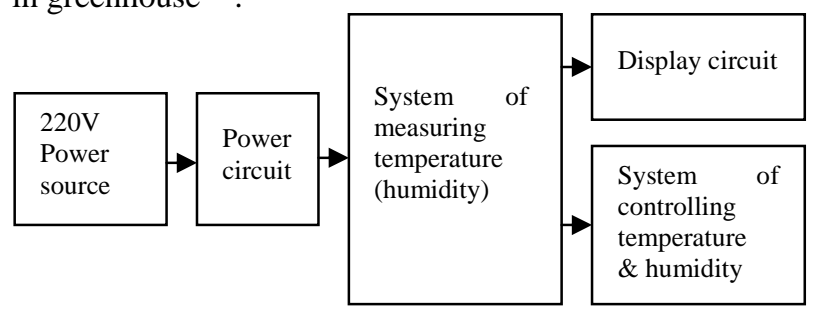

Fig.1 Diagram of greenhouse environment controlling system

\section{COMMON CONTROL EQUIPMENT OF GREENHOUSE}

The heating modes of greenhouse include plumb heating, hot air blower heating through burning oil (coal), electricity heating and radiation heating. The heating system is an essential equipment in Chinese greenhouse. Simultaneously, such equipments are often used as shade net, insulation quilt. In addition, the JDW-150 carbon 
dioxide generator is used to both heating and produce $\mathrm{CO}_{2}$. Ventilation is the most effective measure to improve the air environment of the greenhouse. The ventilation system includes natural ventilation through sunroof and side windows, and compulsive ventilation through axial blowers. In regulating humidity such equipments are often used as centrifugal spray blower, UHP automatic humidification system, wet curtain ventilation system, etc. The artificial fill-light equipments include fluorescent light source, sodium lamp, etc. With the development of artificial light there emerges diode light-emitting technology and laser light source. These light sources can remedy monochromatic and combine different spectral, they are major transformation of the modern fill light technology.

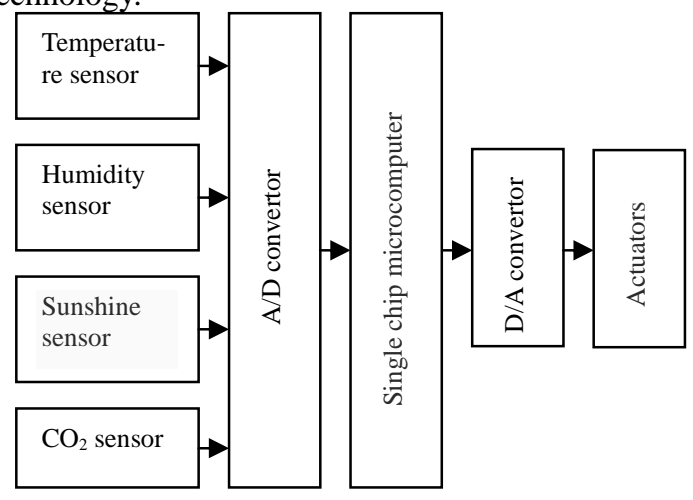

Fig.2 Diagram of single chip microcomputer controlling system

\section{METHODS IN CONTROLLING GREENHOUSE ENVIRONMENT}

\section{A. Single-factor control}

The system often uses integrated circuit, thermistor and hygristor to detect temperature, humidity. In detecting, it starts the controlling equipments at the same time. The system is showed in figure 1 . Such a system only controls single-factor of environment.

\section{B. Multiple factors controlling system}

1) The mode of controlling system based on single chip microcomputer as figure 2.

In single chip microcomputer there saves greenhouse environment factor values which are set according to the law of crop growth. After comparing the saved values with that come from sensors' real-time detection values, the single chip microcomputer uses the compared result to control each actuator motion ${ }^{[4]}$. This kind of controlling mode has such advantages as simple operation and low cost. All the work that comes from information collection to control algorithm is finished by the single chip microcomputer. But there is a serious shortcoming that is the system will out of control as soon as the single chip microcomputer breaks down.

2) The mode of controlling system based on PLC is showed as figure 3 .

It consists of host computer, PLC, data acquisition unit and executive mechanism. It conveys the controlling value of the computer's serial transmission into the controlled module of PLC, simultaneously, it transforms digital signal that comes from the output of the sensor to analog signal by using expansion module of PLC ${ }^{[5]}$. The PLC acts on processing real-time data and transmitting command to regulate and control temperature and intensity of illumination within greenhouse. This controlling system has independent logic controlling function and strong arithmetic ability, but it requires high programming ability and high programming cost.

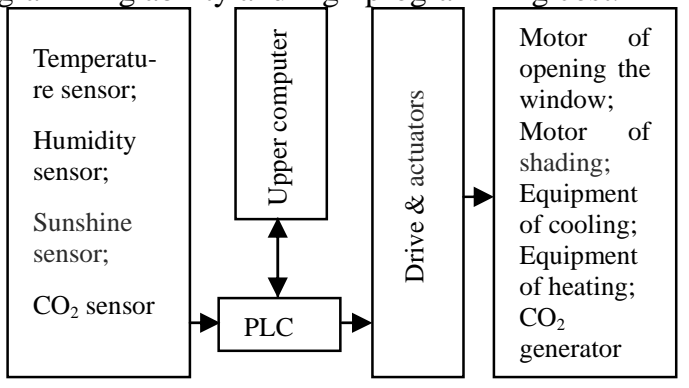

Fig. 3 Diagram of PLC controlling system

3) The mode of controlling system based on the group of single chip microcomputer, PLC and PC.

This kind of system consists of data acquisition system, master controlling system, monitoring system and actuating mechanism, which is showed in figure 4. In here, the single chip microcomputer completes data collection and processing, so it can not only make easy to program with PLC, but also reduce the system's price ${ }^{[6]}$. Therefore, this integrated controlling system is a suitable controlling method in modern greenhouse.

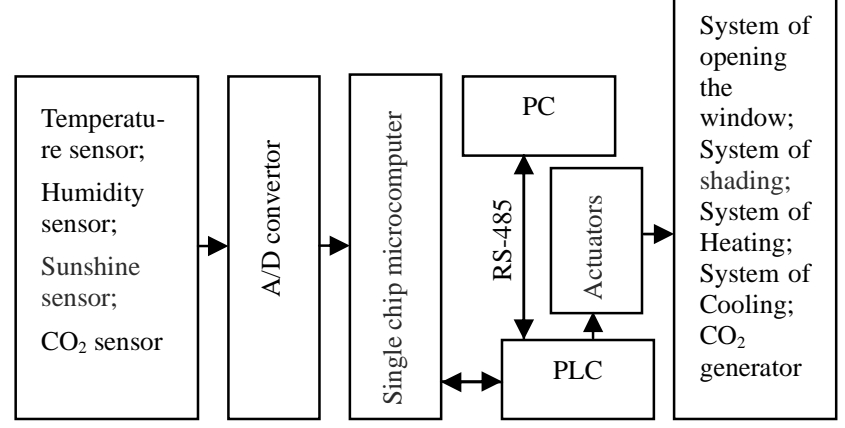

Fig.4 Diagram of PLC \& SCM controlling system

\section{4) The mode of intelligent controlling.}

The intelligent controlling is to construct expert system through collecting the agricultural domain knowledge, technique and various test data, it sets theoretical basis by establishing the mathematical model of plant growth. The technique of greenhouse expert controlling system is an advanced stage of controlling greenhouse. Furthermore, it is a kind of ideal and most promising controlling mode. 


\section{CONCLUSION}

The rapid development of facility agriculture technology brings the greenhouse industry continuously upgrades. Only comprehensively apply such technique as computer technique, automatic control technique, artificial intelligence technique to manage and monitor greenhouse environment can greenhouse modernization and industrialization be realized in real significance. Our country's agricultural facilities started late, only by continuously innovating and gradually perfecting can meet the requirement of agricultural modernization in our country.

\section{REFERENCES}

[1] Deng Zong-bing, Wang Ju. Problems of China' s Agricultural Science and Technology and Their Solutions[J].Technology
Review,2001,14(12):45-47.

[2] Li Ping-ping,Mao Han-ping,Wang Duo-hui.Study on Technique Effect of Greenhouse Environment Factors Controlling and Reasonable Environment Parameters[J].Transactions of the CSAE,1998,14(3):197-201.

[3] Li Gui-dong, Zhang Jin-duo.,Jin Huan-xian. Sensor and Its Application [M].Xi'an: Xi'an university of electronic science and technology press, 2002.

[4] Li Shan-Jun,Zhang Yan-lin. Application Status \& Development Trends of Automatic Control Technology Research on Greenhouse Environment. Agriculture Engineering Technology(Greenhouse \& Horticulture),2008,23(2):20-21.

[5] He Shi-jun,Zhang Lu,Zhang Chi.Design and Application of Intelligent Glass-house Automatic Control System [J].Journal of Henan Agricultural University,2000,34(4):399-401.

[6] He Shi-jun, Xu Jun-feng, Zhang Lu. Application of PLC on Intelligent Greenhouse System [J]. Basic automation, 2000,7(4):53-54. 